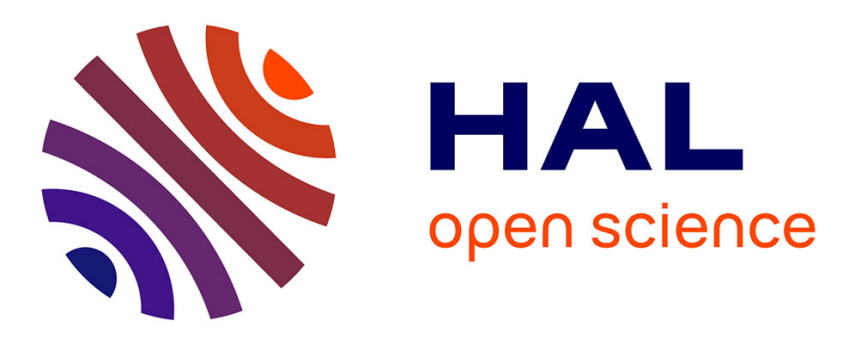

\title{
Through thickness property variations in friction stir welded AA6061 joint fatigued in very high cycle fatigue regime
}

Chao He, Yongjie Liu, Jiangfeng Dong, Qingyuan Wang, Danièle Wagner, Claude Bathias

\section{To cite this version:}

Chao He, Yongjie Liu, Jiangfeng Dong, Qingyuan Wang, Danièle Wagner, et al.. Through thickness property variations in friction stir welded AA6061 joint fatigued in very high cycle fatigue regime. International Journal of Fatigue, 2016, 82, Part 3, pp.379-386. 10.1016/j.ijfatigue.2015.08.013 . hal01687110

\section{HAL Id: hal-01687110 \\ https://hal.parisnanterre.fr/hal-01687110}

Submitted on 18 Jan 2018

HAL is a multi-disciplinary open access archive for the deposit and dissemination of scientific research documents, whether they are published or not. The documents may come from teaching and research institutions in France or abroad, or from public or private research centers.
L'archive ouverte pluridisciplinaire HAL, est destinée au dépôt et à la diffusion de documents scientifiques de niveau recherche, publiés ou non, émanant des établissements d'enseignement et de recherche français ou étrangers, des laboratoires publics ou privés. 


\title{
Through thickness property variations in friction stir welded AA6061 joint fatigued in very high cycle fatigue regime
}

\author{
Chao He ${ }^{\mathrm{a}, \mathrm{c}}$, Yongjie Liu ${ }^{\mathrm{b}}$, Jiangfeng Dong ${ }^{\mathrm{a}}$, Qingyuan Wang ${ }^{\mathrm{a}, *}$, Daniele Wagner ${ }^{\mathrm{c}}$, Claude Bathias ${ }^{\mathrm{c}}$ \\ ${ }^{a}$ Key Laboratory of Energy Engineering Safety and Disaster Mechanics, Ministry of Education, Sichuan University, Chengdu 610065, PR China \\ ${ }^{\mathrm{b}}$ Failure Mechanics and Engineering Disaster Prevention and Mitigation Key Laboratory of Sichuan Province, College of Architecture and Environment, Sichuan University, \\ Chengdu 610065, PR China \\ ${ }^{\mathrm{C}}$ University Paris Ouest Nanterre, LEME Laboratory, 50 Rue de Sèvres, 92410 Ville D'Avray, France
}

Keywords:

Aluminum alloys

Very high cycle fatigue

Friction stir welding

Fatigue crack initiation

Fatigue strength

\begin{abstract}
A B S T R A C T
Ultrasonic fatigue tests were performed on friction stir welded AA6061 joint to investigate very high cycle fatigue (VHCF) behaviors. As a result, almost all the fatigue cracks are initiated from local plastic slip markings around the boundary between thermo-mechanically affected zone and heat affected zone. The fatigue strength decreases from the top to root of the welded joint, owing to the variation of plastic deformation history and temperature distribution through the thickness. In fractography, the fatigue crack initiation site is surrounded by a semicircular flat zone, of which the formation in VHCF regime accounts for more than $98 \%$ of the total fatigue life.
\end{abstract}

\section{Introduction}

Owing to their low density and good mechanical properties, aluminum alloys are increasingly employed in many important manufacturing areas, such as the automobile industry, aeronautics and the military [1]. The structural applications of aluminum alloys inevitably involve welding and joining during manufacturing. Compared with traditional welding processes, friction stir welding (FSW) is a solid state joining method particularly well suited for aluminum and magnesium alloys, which avert a series of disadvantages, such as porosity, cavity and hot cracking [2].

The FSW joints used for automotive or aerospace applications are generally working under cyclic loading conditions, sometimes involving high frequency vibrations. The cyclic loading probably extends beyond a million cycles in their working service [1,3]. Furthermore, the fatigue properties of FSW aluminum alloy welds are highly dependent on the plastic deformation history and local temperature distribution in the weld region, which have been shown to be non-uniform through-thickness under various conditions, such as weld parameters, alloy type and tool geometry [2]. Therefore, it is crucial to understand the fatigue strength and failure mechanism of FSW joint considering the heterogeneity influence

\footnotetext{
* Corresponding author. Tel./fax: +86 02885406919.

E-mail address: wangqy@scu.edu.cn (Q. Wang).
}

in very high cycle fatigue (VHCF) regime. However, current studies on the fatigue properties of the FSW are focused primarily on the fatigue crack propagation resistance, low cycle fatigue behavior and high cycle fatigue property [4-6]. In particular, the investigations on the fatigue strength and failure mechanism considering the heterogeneity through-thickness of FSW joint are extremely limited, especially in the VHCF regime.

In this test, the variations of microstructure and hardness, which are closely related to the heterogeneities, are measured by the optical microscope and sclerometer. Then, ultrasonic fatigue tests $(20 \mathrm{kHz})$ are performed on full and partial thickness specimens of AA6061 friction stir welded joint to further investigate the effect of heterogeneities at different cross section heights on the fatigue life in the VHCF regime. Finally, the location of fatigue failure across the weld, fatigue crack initiation and propagation behaviors will be discussed based on the fractographic analysis.

\section{Experimental procedure}

The material utilized in this investigation is 6061-T651 aluminum alloy with a sheet thickness of $10 \mathrm{~mm}$, and its nominal chemical compositions and mechanical properties are listed in Tables 1 and 2, respectively. The rolled plate had a solution treatment in $529^{\circ} \mathrm{C}$, followed by aging treatment in $160^{\circ} \mathrm{C}$ for $18 \mathrm{~h}$. The butt joints were made using a FSW machine, and the welding 
Table 1

Chemical compositions of 6061-T651 aluminum alloy (wt.\%).

\begin{tabular}{|c|c|c|c|c|c|c|c|c|c|c|}
\hline \multirow[t]{2}{*}{$\mathrm{Cr}$} & \multirow[t]{2}{*}{$\mathrm{Cu}$} & \multirow[t]{2}{*}{$\mathrm{Fe}$} & \multirow[t]{2}{*}{$\mathrm{Mg}$} & \multirow[t]{2}{*}{ Mn } & \multirow[t]{2}{*}{$\mathrm{Si}$} & \multirow[t]{2}{*}{$\mathrm{Ti}$} & \multirow[t]{2}{*}{$\mathrm{Zn}$} & \multicolumn{2}{|c|}{ Other impurities } & \multirow[t]{2}{*}{$\mathrm{Al}$} \\
\hline & & & & & & & & Each & Total & \\
\hline $0.04-0.35$ & $0.15-0.40$ & 0.70 & $0.80-1.2$ & 0.15 & $0.40-0.80$ & 0.15 & 0.25 & 0.05 & 0.15 & Rest \\
\hline
\end{tabular}

Table 2

Mechanical properties of 6061-T651 aluminum alloys.

\begin{tabular}{lllll}
\hline $\begin{array}{l}\text { Ultimate } \\
\text { strength (MPa) }\end{array}$ & $\begin{array}{l}\text { Yield strength } \\
(\mathrm{MPa})\end{array}$ & $\begin{array}{l}\text { Modulus of } \\
\text { elasticity (GPa) }\end{array}$ & $\begin{array}{l}\text { Poisons } \\
\text { ratio }\end{array}$ & $\begin{array}{l}\text { Elongation } \\
(\%)\end{array}$ \\
\hline 310 & 276 & 68.9 & 0.33 & 12 \\
\hline
\end{tabular}

direction was perpendicular to the rolling direction as shown in Fig. 1a. The tool consisted of a $24 \mathrm{~mm}$ diameter curved profile shoulder with an $\mathrm{M} 10 \times 1$ threaded pin $(10 \mathrm{~mm}$ diameter in root, $7 \mathrm{~mm}$ diameter in head and $9.2 \mathrm{~mm}$ in the length). The tilt angle of the rotating tool was $2^{\circ}$ with respect to $Z$-axis of FSW machine. A tool rotary speed of $600 \mathrm{rpm}$ was used in conjunction with a traverse speed of $400 \mathrm{~mm} / \mathrm{min}$.

After welding, $1 \mathrm{~mm}$-thick layers from both top and root sides of the welded plates were skimmed to remove the profile irregularities. Full thickness specimens were sectioned perpendicular to the welding direction with the detailed sizes shown in Fig. 1b. To fabricate sub-thickness specimens from each 1/4 layer through-thickness, a full-thickness specimen was sliced at different heights into four partial specimens with a wire-cutting machine as presented in Fig. 1c. Note that some material was lost due to machining, such that the sum of the thicknesses of the partial specimens does not match that of the full thickness specimen. For surface observation, the weld cross-sections of all tested specimens were first polished using different grades of emery paper and then subjected to electrolytic etching at $30 \mathrm{~V}$ for $90 \mathrm{~s}$ using perchloric acid/ethanol solution to reveal the microstructure. The residual stress was measured by X-ray diffraction $\sin ^{2} \psi$ method, the transverse residual stress in un-skimmed plate state is about $-14 \mathrm{MPa}$ on the top surface, which is much smaller than that in the longitudinal direction (76 MPa). Generally, the residual stress in the FSW joints were quite low compared to

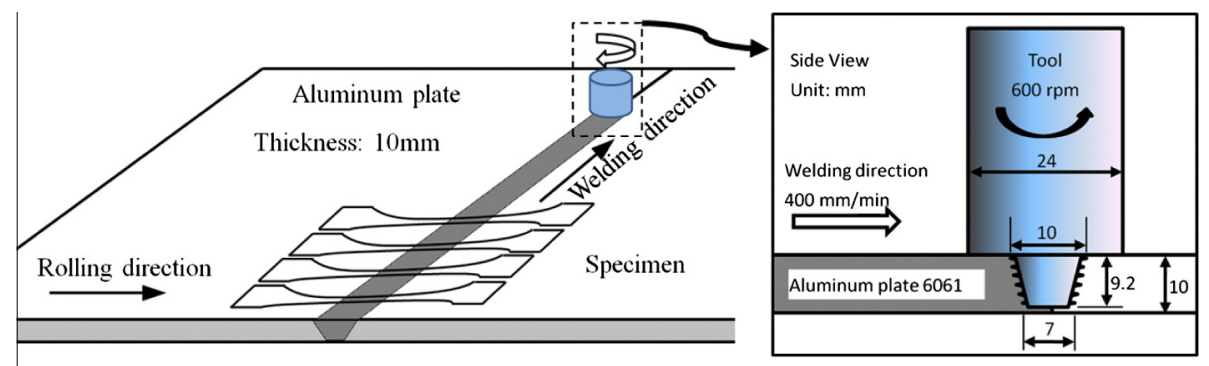

(a)

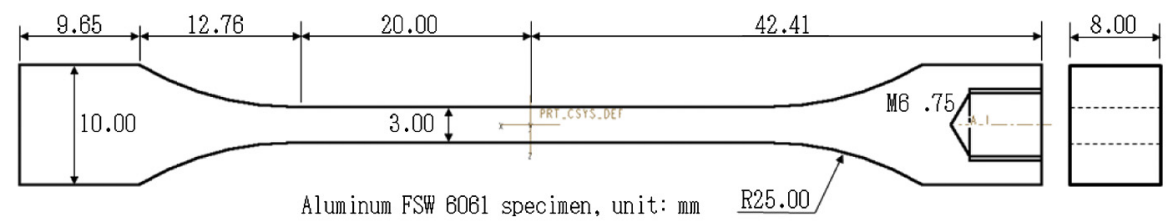

(b)

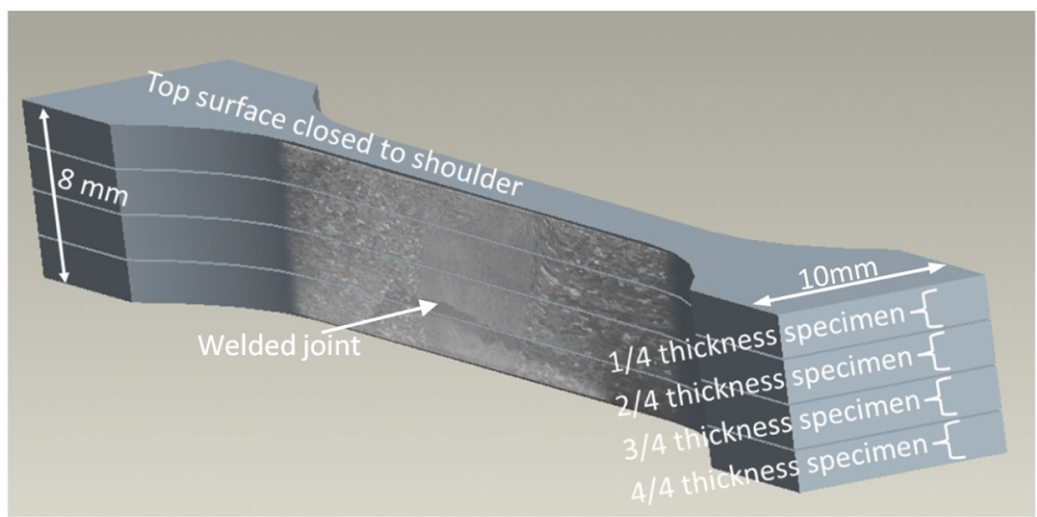

(c)

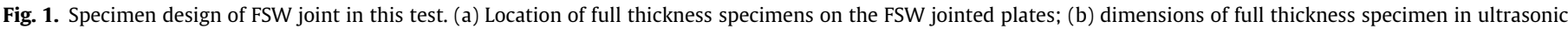
fatigue test; (c) schematic illustration of the partial specimen through thickness 
those generated during fusion welding, and the longitudinal residual stress were tensile and transverse residual stress were compressive [2]. After skimming, the maximum value (-5.7 $\mathrm{MPa})$ of residual stress in transverse direction was located at the border of weld nugget. Therefore, the influence of residual stress on the fatigue behaviors in this test was neglected concerning the stress relaxation during specimen machining.

Fatigue tests were performed on an ultrasonic fatigue test system up to a limit of $10^{9}$ cycles at a constant stress ratio of $R=-1$ and at room temperature. When the fatigue crack nucleated and propagated, the natural frequency of ultrasonic loading system would decrease during the test. In this investigation, the fatigue tests would stop automatically when the variation of frequency exceeded $\pm 500 \mathrm{~Hz}$. Fatigued specimens were examined by scanning electron microscope (SEM) and optical microscope (OM) to characterize the fatigue failure mechanisms.

\section{Results}

\subsection{Microstructure and hardness distribution}

Fig. 2 shows typical microstructures of a weld cross section perpendicular to the welding direction. The nugget zone (NZ) consists of fine and equiaxed grains after recrystallization induced by intense plastic deformation and frictional heating during FSW process. The grains in thermo-mechanically affected zone (TMAZ) are characterized by a highly deformed structure, which were deformed in an upward flowing pattern around the nugget zone. In heat affected zone, the material experiences a thermal cycle, but does not undergo any plastic deformation, so the HAZ retains the same grain structure as the base material (BM). Generally, the plastic deformation and friction heat during FSW through the thickness are nonuniform, which generate different microstructures at different heights. Therefore, it can be inferred that the microstructural changes at different heights had a significant effect on post weld fatigue properties.

As a precipitation hardenable alloy, the hardness profile of AA6061 FSW joint is much more influenced by the size, volume and distribution of the precipitates. Fig. 3 reveals the typical microhardness distributions at three heigths (top, middle and bottom). It is found that the hardness of HAZ decreases gradually toward the center of the weld, and reaches the minimum at the boundary between the TMAZ and HAZ at advancing side (AS), which exhibits a W-shaped appearance. The soft zone in the HAZ can be attributed to the dissolution and coarsening of strengthening phase induced by heating during FSW [7]. The hardness decreases dramatically at the boundary of TMAZ and NZ because of the variation of grain size between them. The TMAZ and NZ both undergo severe intense plastic deformation and thermal cycle. In the NZ, the dissolution of precipitate results in the softening, but fine and equiaxed grains bring the increase of hardness according to Hall-Petch relationship

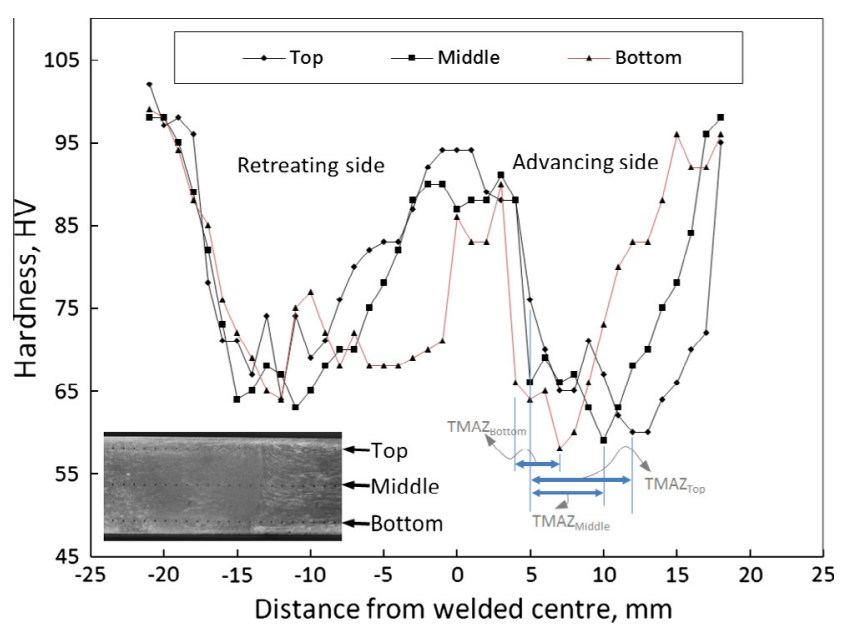

Fig. 3. Hardness transverse to weld at various depths through thickness for FSW joint.

[8]. Therefore, the hardness of the weld zone is found to be much higher than that in TMAZ and HAZ, but slightly lower than that of base material. It should be noted that the width of soft zone decreases from top to bottom of the specimen, which can be attributed to heterogeneities of peak temperature and thermal cycle duration through the thickness.

\section{2. $S-N$ curves}

Fatigue data of AA6061 friction stir welds for full and partial thickness specimens are shown in Fig. 4, in which arrows indicate runout specimens at $10^{9}$ cycles. Curved lines are used to approximate data with Basquin equation for each group of test in the single logarithm. Interestingly, no fatigue limits can be observed for five groups of tests in the VHCF regime. The fatigue strength of full thickness specimen at $10^{9}$ cycles is about $65 \mathrm{MPa}$, which accounts for about $59.1 \%$ of AA6061-T6 base material with ultrasonic loading [1]. The decrease of fatigue strength in the VHCF regime compared to base material seems to be less than that of traditional fusing welds (only about $40 \%$ fatigue strength of base material) [9]. It is believed that FSW method could improve the fatigue strength of the welds for the lacking of inherent defects or internal flaws [2]. In addition, the FSW partial thickness specimens have lower fatigue strength than that of base material in this study, and the fatigue life through the thickness is found to be different, which decreased from top to root side of the FSW weld. These changes of fatigue strength for partial specimens can be attributed to the variation of microstructure and plastic deformation during the FSW processing, and these will be discussed in detail in the following sections.

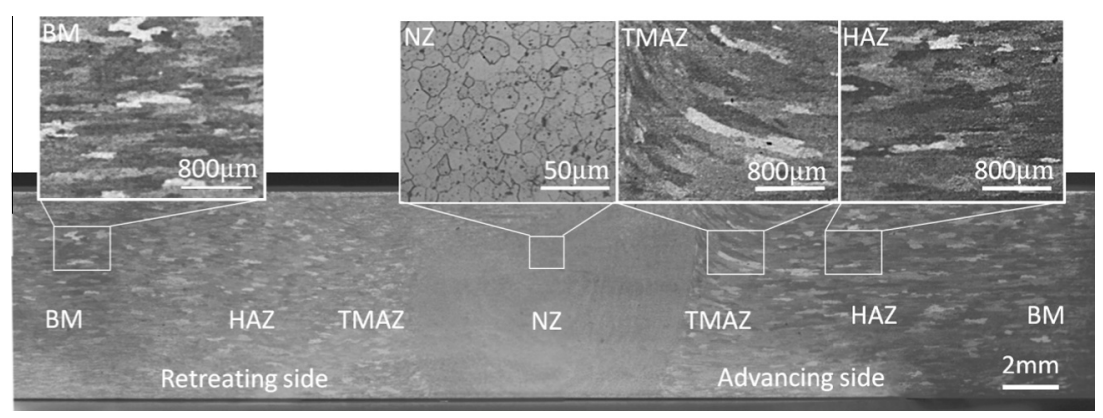

Fig. 2. Metallographic cross-section of the FSW weld. 


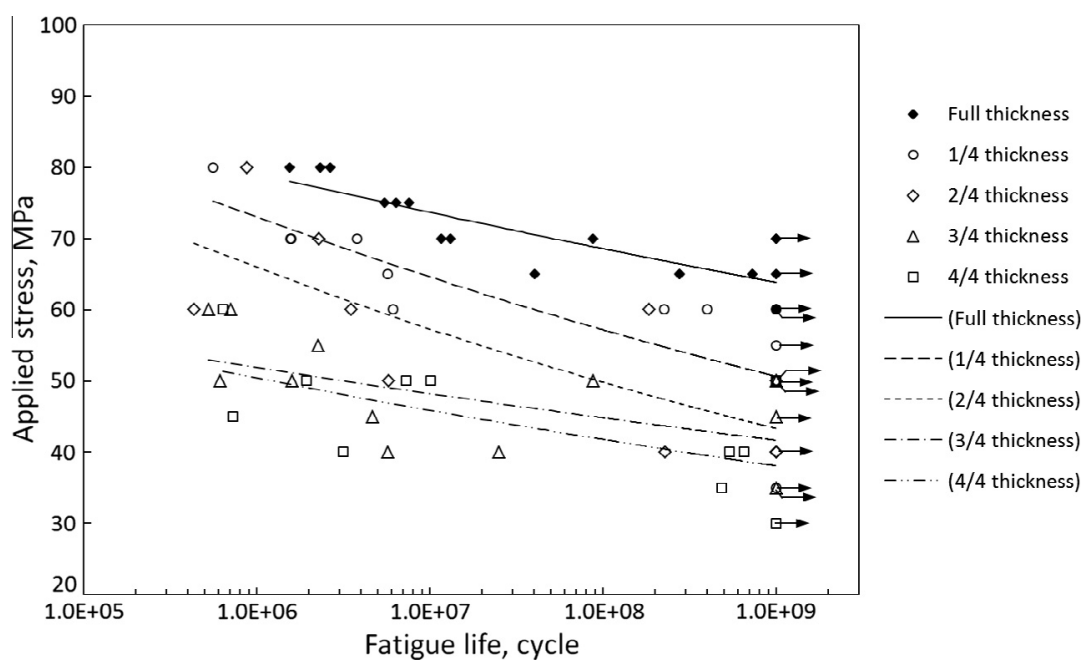

Fig. 4. Fatigue data of full thickness and partial specimens.

\subsection{Fractography}

Fracture surfaces of all full thickness specimens were observed by SEM after the final failure. Fig. 5 shows representative fracture morphologies of two specimens failed at short fatigue life region. It is evident that fatigue crack initiation sites are located at the specimen surface, and there is a semicircular flat zone (plotted with solid line in Fig. 5) with a radius of about $120 \mu \mathrm{m}$ surrounding the crack initiation site. The fracture surface out of the flat zone consists of many paralleled glide planes as indicated by arrows in Fig. 5. From the distribution characteristics of glide planes, grain boundaries (plotted with dash lines) can be identified due to the fact that the paralleled glide planes in the neighborhood grains are oriented in different directions. Therefore, it can be found that the crack in Fig. $5 \mathrm{a}$ initiated from the interior of grain A and propagated through the boundary between the grain $A$ and $C$. As a result, the flat zone eventually ended in the interior of grain $A$ and C. In Fig. 5b, the edge of flat zone is located just at the boundary of grain D. For the specimens failed in the VHCF regime, the flat zone surrounding the fatigue crack initiation site can also be observed in Fig. 6a and b, whereas the size of the flat zone is much larger (about $400 \mu \mathrm{m}$ in radius) than that at short fatigue region, and grain boundaries could not be identified based on the characteristics of sliding planes.

\section{Discussions}

\subsection{Locations of the crack initiation sites in full thickness specimen}

In this study, the fractographies of all full thickness specimens present surface crack initiation features, which were totally different from the internal crack initiation mechanisms for many metallic materials in the VHCF regime [10]. It has been reported that some ductile metals exhibit surface crack initiation sites [11-13], but the welded joints of these materials by fusion welding method usually had internal fatigue crack initiation sites induced by welding defects, which decreased the fatigue strength dramatically $[9,14]$. The fatigue crack initiation is extremely sensitive to the internal defects, but successful FSW welds generally contains no inherent defects or internal flaws. Because of that, the fatigue crack initiated from the specimen surface in this test, and the FSW method improves the fatigue strength of welded joints as compared to fusion welding method.
The specimen in transverse direction in this test contains microstructures from all four zones, i.e., BM, HAZ, TMAZ and NZ, each of which experiences different histories of plastic deformation and high-temperature exposure [2]. Therefore, the resistances to fatigue crack initiation, identified as a predominant role on the metallic fatigue failure mechanism in the VHCF regime $[10,15,16]$, are inconsistent across the welds, which result in the fatigue failures occurring just in the weakest zone. The fracture surfaces were examined by OM and SEM to determine the locations of fatigue crack initiation sites. The results are plotted in one specimen surface approximately as shown in Fig. 7, in which fatigue lives are also presented by different colored dots. It can be observed that fatigue crack initiation sites, leading to the fatigue failure, are located mainly around the boundary between the TMAZ and HAZ at the advancing side except one dot in the NZ, which are in accordance with the locations of the lowest hardness points as presented in Fig. 3. During FSW process, the high-temperature experienced in both TMAZ and HAZ resulted in the dissolution of strengthening precipitates and the formation of precipitate free zone (PFZ) $[17,18]$, so the hardness in these zones were degraded accordingly as compared with BM. On the other hand, severe plastic deformation (only existed in TMAZ) also exerted a significant effect on the mechanical behavior, which increased the hardness in the TMAZ due to the effect of strain hardening [19]. Because of the complex effect from both high temperature and plastic deformation, the hardness in the TMAZ is higher than that in the HAZ adjacent to the TMAZ, and a weak zone in mechanical properties formed accordingly around the boundary between the TMAZ and HAZ. Therefore, in tensile or fatigue testing, the strain localized in this weak zone [20,21], which is vulnerable to the formation of local slip bands, and then led to the initiation of fatigue crack $[12,22]$. In addition, it should be noted that the interface between the TMAZ and HAZ is diffuse at the retreating side (RS) as indicted in Fig. 2, so the strain concentration is less serious than that at the advancing side. Therefore, no fatigue crack initiation occurred at the retreating side in this work.

\subsection{Heterogeneity of fatigue strength through thickness in VHCF range}

The fatigue strength of partial specimens decreased from the top to root layer based on the analysis on $\mathrm{S}-\mathrm{N}$ curves as presented in Fig. 4. The heterogeneities of fatigue strength through the thickness from high cycle fatigue (HCF) to VHCF range were confirmed 


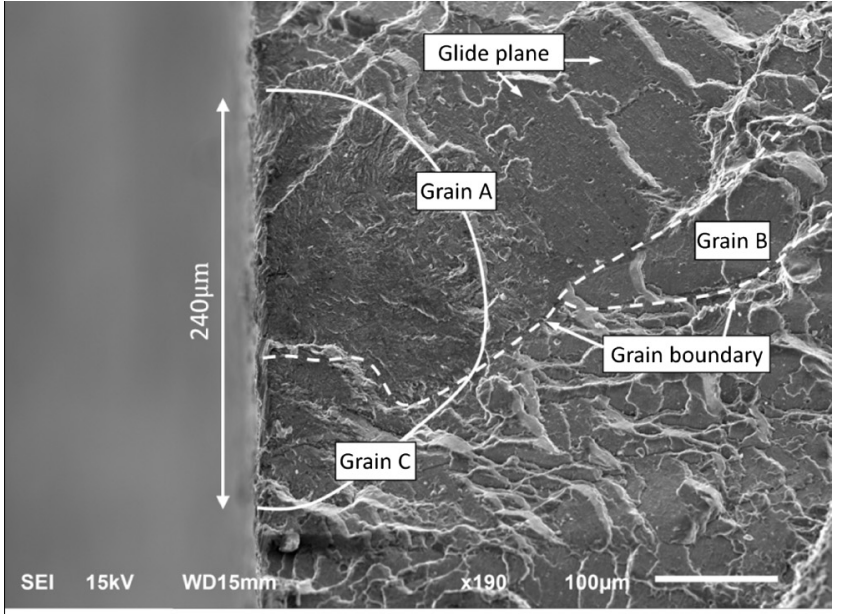

(a)

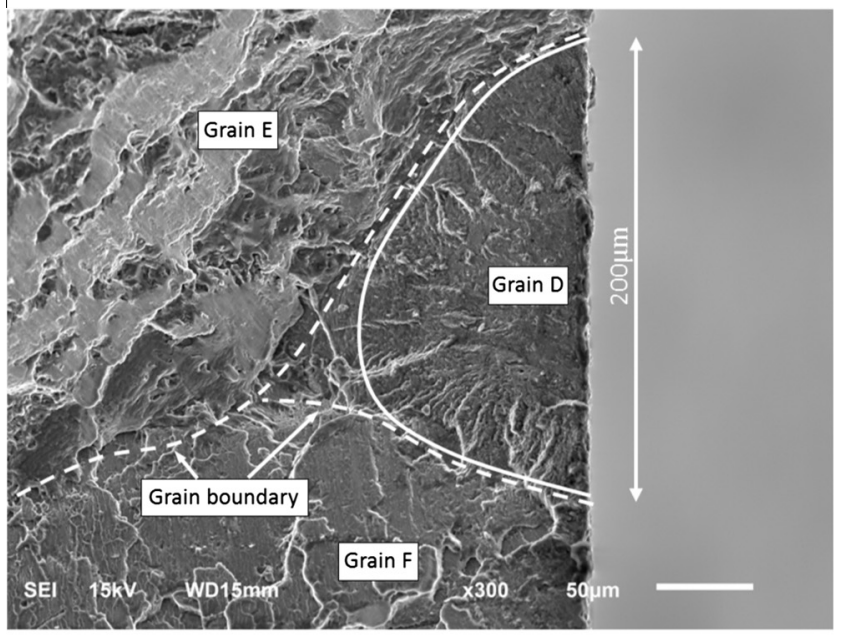

(b)

Fig. 5. Fracture surface observation of crack initiation site at short fatigue life region. (a) $N_{f}=6.39 \times 10^{6}$ cycles, $\sigma_{b}=75 \mathrm{MPa}$; (b) $N_{f}=2.32 \times 10^{6}$ cycles, $\sigma_{b}=$ $80 \mathrm{MPa}$.

because of the microstructure evolution. It has been discussed that the mechanical behaviors across the welds were influenced by not only high temperature experience (degradation of strength), but also plastic deformation (strain hardening). The temperature increase around the stirred zone during FSW has been investigated by some researchers $[17,23]$. It was found that the top side of the weld generally exhibited higher temperatures compared to the bottom side due to the heating generating from the tool shoulder, while the bottom surface was in contact with the backing plate, which acted as a heat sink [24]. However, the lowest hardness point at the top side in this test is slightly higher than the one at the bottom as shown in Fig. 3, and similar results could also be found in some researches [24,25]. This can be attributed to the strain hardening caused by deformed microstructure in the TMAZ, of which the width decreased from the top to bottom side. As a result of the combined effect of intense plastic deformation and temperature cycle, the softest zone is located at the bottom side of specimen, which results in the lowest fatigue strength of $4 / 4$ thickness specimen as presented in the S-N curves (Fig. 4). Moreover, through the distribution of fatigue crack initiation sites in Fig. 7, there is a tendency of fatigue crack initiation location transforming from bottom to top side of the weld as the increasing of fatigue life up to the VHCF regime. This is due to the fact that

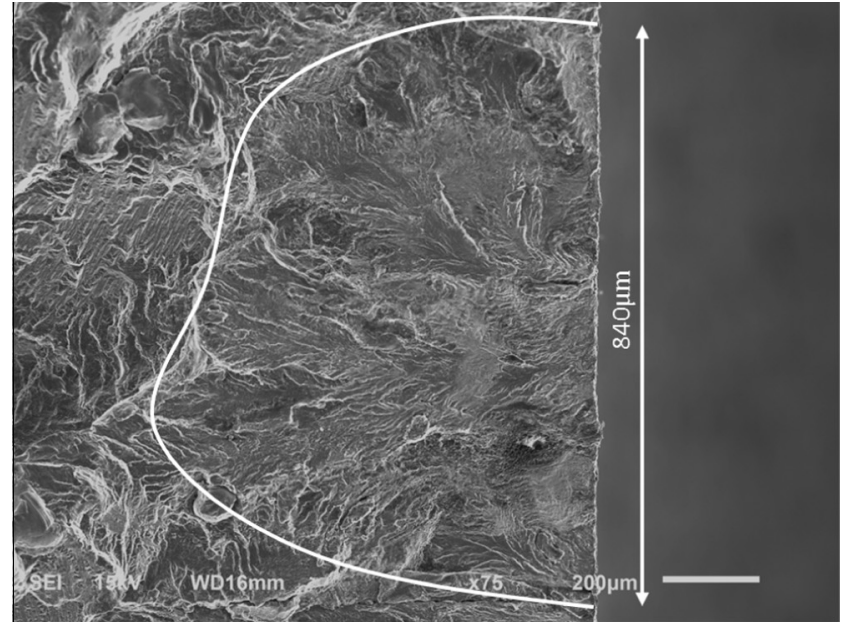

(a)

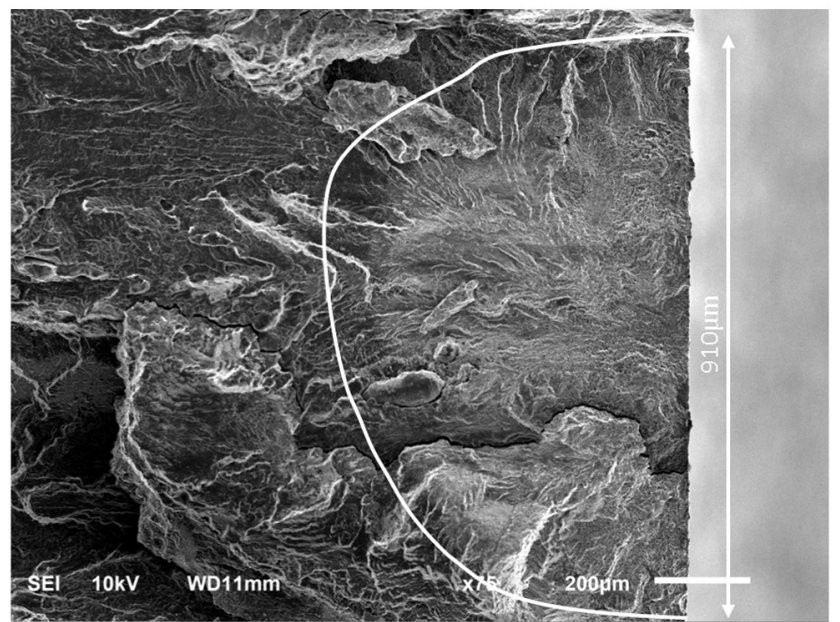

(b)

Fig. 6. Crack initiation site observation in VHCF for the specimens of (a) $N_{f}=2.78$ $\times 10^{8}$ cycles, $\sigma_{b}=65 \mathrm{MPa}$ and (b) $N_{f}=7.32 \times 10^{8}$ cycles, $\sigma_{b}=65 \mathrm{MPa}$.

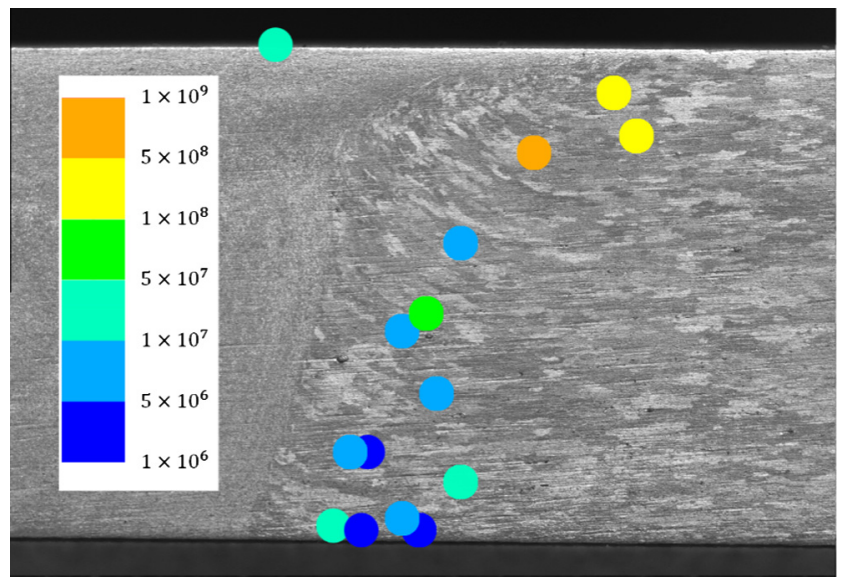

Fig. 7. Schematic diagram of the crack initiation site location on the specimen surface.

the soft zone at the top is larger than that at the bottom of the specimen as presented in hardness profiles in Fig. 3, which increases the probability of fatigue crack initiation at the top side in the VHCF regime [3]. 


\subsection{Fatigue crack initiation mechanism}

In the VHCF domain for metallic materials, it has been confirmed that more than $90 \%$ of the total life devoted to the fatigue crack initiation process [15]. For this reason, a lot of work has been performed on the crack initiation mechanisms in qualitative and quantitative ways [26-28]. In this section, the fatigue crack initiation and propagation mechanisms will be discussed for a better understanding of the fatigue failure of FSW joint.

Fig. 8 presents the specimen surface with a fatigue crack locating between the TMAZ and HAZ. At the fatigue crack initiation site as shown in Fig. 8b, Persistent slip bands could be observed locally in an area as plotted with dash line, from where the fatigue crack were initiated. The same fatigue crack initiation mechanisms in the VHCF regime, the development of persistent slip bands leading to the surface fatigue cracks, can also be observed in some single phase metals [11,29-32]. Generally, the plastic deformation features for these materials were extensive on the specimen surface, but in this work the persistent slip bands seem to be limited in a very local small region distributed sporadically at the boundary between the TMAZ and HAZ due to the heterogeneities of

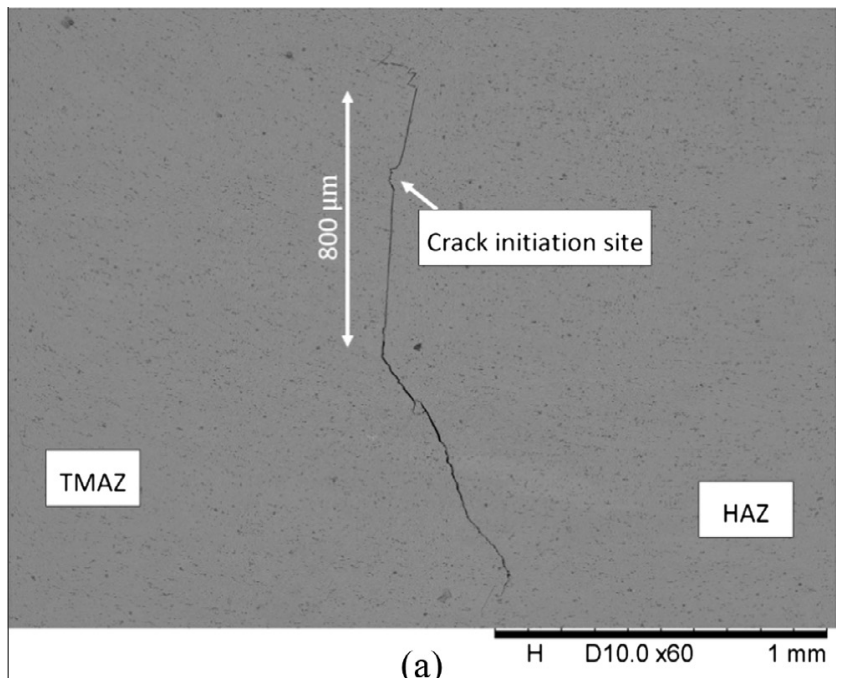

(a)

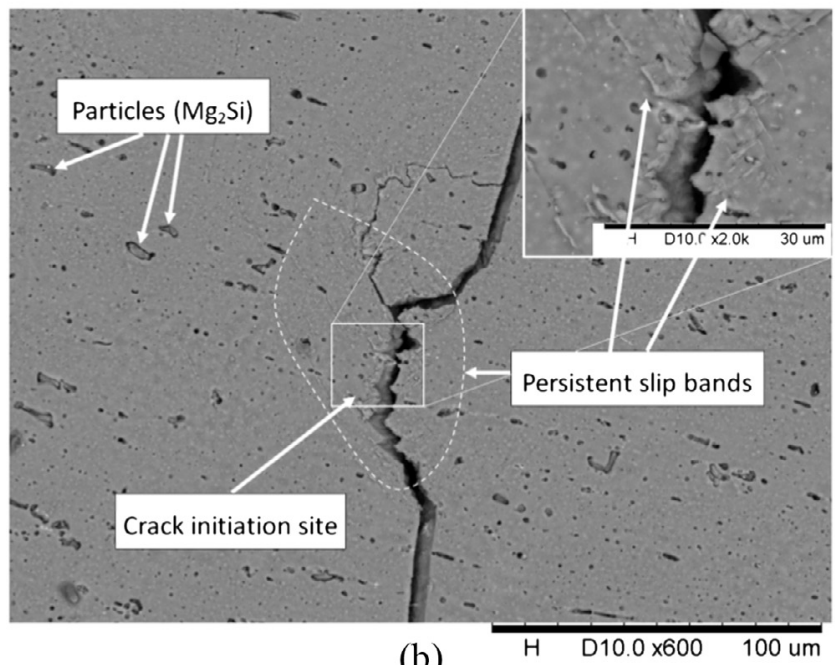

(b)

Fig. 8. SEM observations of a fatigue crack on specimen surface $\left(N_{f}=8.74 \times 10^{7}\right.$ cycles, $\sigma_{b}=70 \mathrm{MPa}$ ). (a) The crack locating between TMAZ and HAZ with whole morphology; (b) enlargement of the fatigue crack initiation site showing persistent slip bands. microstructural and mechanical properties. In Fig. 8a, the crack path close to the initiation site is perfectly straight and perpendicular to the direction of stress. Persistent slip bands could not be found around the crack face within a length of $800 \mu \mathrm{m}$, which corresponds to the semicircular flat zone mentioned in fractography analysis. It seems to be the fact that the size of the flat zone is influenced by not only the amplitude of applied stress, but also the grain size at short fatigue life region, because the border of the flat zone can be situated both in the interior of a big grain as shown in Fig. 5a and at the grain boundary as presented in Fig. 5b. But in the VHCF regime, the effect of grain size on the dimension of the flat zone is vanished based on the observation in Fig. $6 a$ and $b$, because the diameter of the flat zone (about $800 \mu \mathrm{m}$ ) is much larger than the average grain size perpendicular to the loading direction (about $200 \mu \mathrm{m}$ ).

The effective fatigue stress intensity factor $\Delta K$ at the end of the flat zone was calculated for all failed specimens according to the computing method for semicircular crack in infinite solid [33], and the results were presented in Fig. 9a. For comparisons, the effective stress intensity threshold values for AA 6061 obtained both from the experimental results by Paris [34] (measured at conventional frequency fatigue test) and Herzberg's prediction [35] were also plotted. It can be seen that the results of the stress intensity factor of the flat zones in this test varies in the range of 0.89$1.59 \mathrm{MPa} \sqrt{ } \mathrm{m}$, which is in good agreement with the results about propagation threshold of fatigue crack propagation rate by Paris

(a)
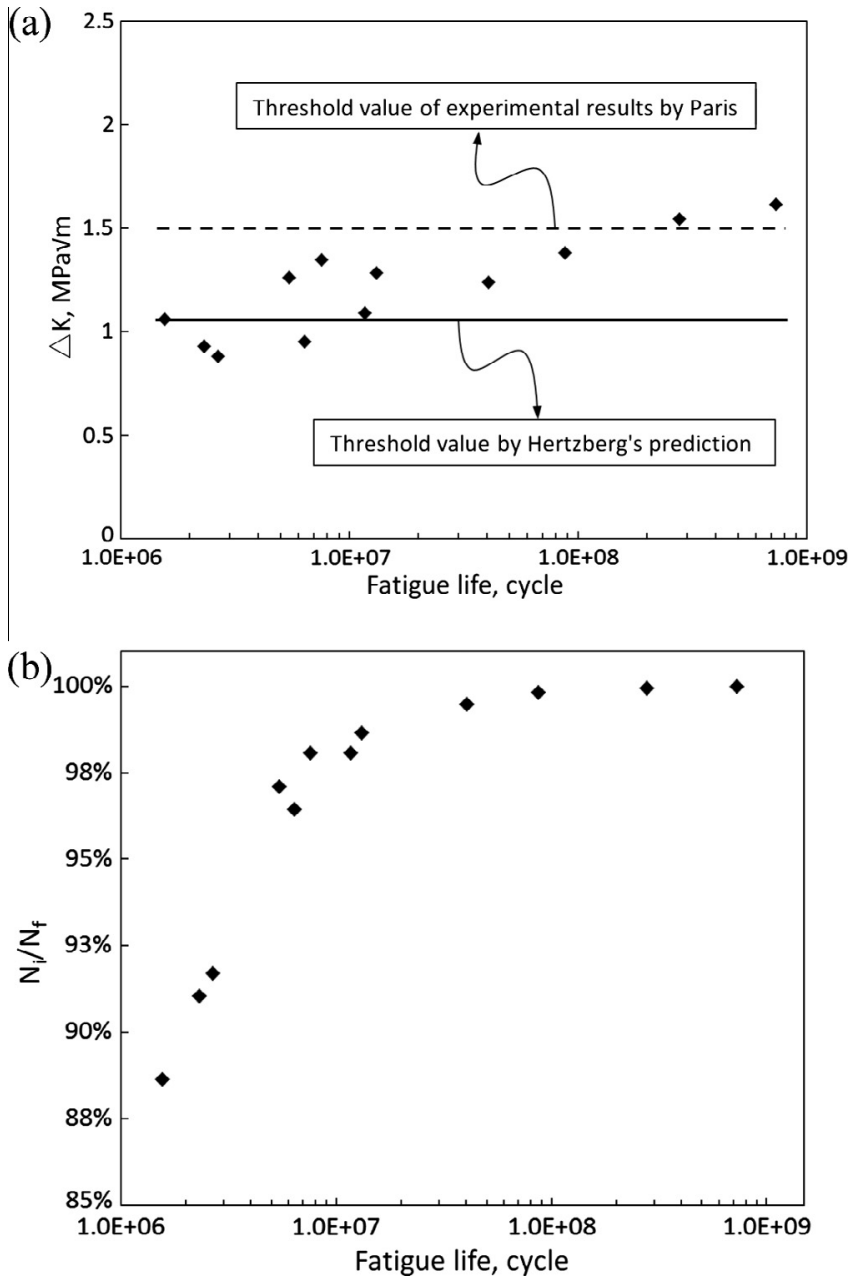

Fig. 9. Stress intensity factor range of the flat zone surrounding the crack initiation site (a) and normalized crack initiation life (b) as a function of total fatigue life. 
(1.5 MPa $\sqrt{ } \mathrm{m}$ ) and Herzberg (1.1 MPa $\sqrt{ } \mathrm{m})$. Frequency effect of ultrasonic loading on the determination of stress intensity threshold is negligible for FSW aluminum alloys. The stress intensity factor threshold in the VHCF range, according to the fatigue crack initiation sites located at the top zone, is slightly higher than at the root zone of the welds, because the fatigue strength of partial thickness specimen decreased from the top to root of the welds as shown in Fig. 4. Moreover, the formation of the flat zone can be regarded as the fatigue crack initiation process, because the value of $\Delta K_{\text {Flat zone }}$ corresponds to the $\Delta K_{\text {th }}$.Therefore, Paris law is acceptable to describe the fatigue crack growth process after the

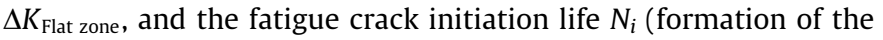
flat zone) can be estimated with the following expressions:

$$
\begin{aligned}
& \frac{d a}{d N}=C \Delta K^{m} \\
& N_{p}=\frac{2}{(m-2) C Y^{m} \Delta \sigma^{m}}\left[\frac{1}{a_{\text {flat }}^{(m-2) / 2}}-\frac{1}{a_{\text {critical }}^{(m-2) / 2}}\right] \\
& N_{i}=N_{f}-N_{p}
\end{aligned}
$$

where $C$ and $m$ are the parameters in relation with the given material and are obtained from the results of crack propagation test on base material (AA6061) by Paris [34] $\left(C=6.02 \times 10^{-9}, m=3.157\right)$, and $Y$ is the related shape factor $\left(Y=\frac{2.05}{\pi}\right) . a_{\text {critical }}$ is critical crack length corresponding to the fracture roughness $\left(a_{\text {critical }}=8.54 \mathrm{~mm}\right.$, equal to the maximum length of specimen for conservative prediction). Note that the fatigue crack nucleated and propagated approximately along the boundary between the TMAZ and HAZ, where the microstructure kept almost the same in shape and size as compared to base materials, so the effect of microstructure changes on the fatigue crack propagation rate was neglected in this test. The values of $N_{i} / N_{f}$ for all failed full thickness specimen are obtained and plotted in Fig. 9b. It is observed that the value of $N_{i} / N_{f}$ increases dramatically with the increasing of total fatigue life. This differs greatly from the VHCF failure mechanisms of the TIG welded joints that the fatigue crack propagated directly from the welding defects without apparent initiation process [9], which the life ratio $N_{i} / N_{f}$ for $\mathrm{FZ}$ specimens was scattered. when the fatigue life is above $10^{7}$ cycles, the crack initiation life contributing to the formation of the flat zone is more than $98 \%$. It is evident that the fatigue life in AA6061 friction stir welded joint is almost occupied by the crack initiation process of the flat zone formation.

\section{Conclusions}

In this study, ultrasonic fatigue tests were performed on FSW aluminum alloy joints to investigate the heterogeneities of fatigue behaviors through the thickness. The conclusions can be summarized as follows:

(1) The S-N curves of FSW joints for both full and partial thickness specimens show continuous decrease with the decrease of the stress amplitude, and there is no fatigue limit in the very high cycle fatigue regime.

(2) For full thickness specimens, fatigue crack initiation sites were located around the boundary between the TMAZ and HAZ due to material soften caused by plastic deformation and high temperature experience.

(3) For partial thickness specimens, fatigue behaviors is found to be heterogeneous through the thickness, for that the fatigue strength decreased from the top to root of the welds.

(4) Persistent slip bands could be found locally at the fatigue crack initiation site. The fatigue crack initiation site was surrounded by a flat zone, of which the formation occupied over $98 \%$ of the total fatigue life in VHCF regime.

\section{Acknowledgements}

This work was financially supported by the National Natural Science Foundation of China (No. 11172188, No. 11302142 and No. 51408382) and the Program for Changjiang Scholars and Innovative Research Team (IRT14R37). Support of Dr. Jiukai Li and Renhui Tian is highly acknowledged.

\section{References}

[1] Wang QY, Li T, Zeng XG. Gigacycle fatigue behavior of high strength aluminum alloys. Fatigue 2010;2(1):65-70.

[2] Mishra RS, Ma ZY. Friction stir welding and processing. Mater Sci Eng R-Rep 2005;50(1-2):1-78.

[3] Bathias C, Drouillac L, Le Francois P. How and why the fatigue S-N curve does not approach a horizontal asymptote. Int J Fatigue 2001;23: S143-51.

[4] Ni DR et al. Residual stresses and high cycle fatigue properties of friction stir welded SiCp/AA2009 composites. Int J Fatigue 2013;55:64-73.

[5] Grujicic M et al. Statistical analysis of high-cycle fatigue behavior of friction stir welded AA5083-H321. J Mater Eng Perform 2011;20(6):855-64.

[6] Ilman MN, Kusmono, Iswanto PT. Fatigue crack growth rate behaviour of friction-stir aluminium alloy AA2024-T3 welds under transient thermal tensioning. Mater Des 2013;50:235-43.

[7] Iordachescu M et al. Fsw - characteristic flaws in aluminium alloys joints. Metalurgia Int 2009;14:135-8.

[8] Hall E. The deformation and ageing of mild steel: III discussion of results. Proc Phys Soc Sect B 1951;64(9):747.

[9] He C et al. Fatigue damage evaluation of low-alloy steel welded joints in fusion zone and heat affected zone based on frequency response changes in gigacycle fatigue. Int J Fatigue 2014;61:297-303.

[10] Wang QY et al. Effect of inclusion on subsurface crack initiation and gigacycle fatigue strength. Int J Fatigue 2002;24(12):1269-74.

[11] Phung NL et al. Very high cycle fatigue of copper: Evolution, morphology and locations of surface slip markings. Int J Fatigue 2014;63:68-77.

[12] Mughrabi H. Microstructural fatigue mechanisms: cyclic slip irreversibility, crack initiation, non-linear elastic damage analysis. Int J Fatigue 2013;57:2-8.

[13] Mughrabi H. Specific features and mechanisms of fatigue in the ultrahighcycle regime. Int J Fatigue 2006;28(11):1501-8.

[14] Zhu ML et al. Very high cycle fatigue behavior of a low strength welded joint at moderate temperature. Int J Fatigue 2012:40:74-83.

[15] Wagner D et al. Fatigue crack initiation detection by an infrared thermography method. Fatigue Fract Eng Mater Struct 2010;33(1):12-21.

[16] Marines-Garcia I et al. Fatigue crack growth from small to long cracks in VHCF with surface initiations. Int J Fatigue 2007:29(9-11):2072-8.

[17] Sato YS et al. Microstructural evolution of 6063 aluminum during friction-stir welding. Metall Mater Trans a-Phys Metall Mater Sci 1999;30(9):2429-37.

[18] Su JQ et al. Microstructural investigation friction stir welded 7050-T651 aluminium. Acta Mater 2003;51(3):713-29.

[19] Chowdhury SM et al. Tensile properties of a friction stir welded magnesium alloy: effect of pin tool thread orientation and weld pitch. Mater Sci Eng aStruct Mater Prop Microstruct Process 2010;527(21-22):6064-75.

[20] Genevois C, Deschamps A, Vacher P. Comparative study on local and global mechanical properties of 2024 T351, 2024 T6 and 5251 O friction stir welds. Mater Sci Eng a-Struct Mater Prop Microstruct Process 2006;415(1-2):162-70.

[21] Boyce BL, Reu PL, Robino CV. The constitutive behavior of laser welds in 304L stainless steel determined by digital image correlation. Metall Mater Trans aPhys Metall Mater Sci 2006;37A(8):2481-92.

[22] Wang $C$ et al. Dissipative and microstructural effects associated with fatigue crack initiation on an Armco iron. Int J Fatigue 2014;58:152-7.

[23] Murr LE, Liu G, McClure JC. A TEM study of precipitation and related microstructures in friction-stir-welded 6061 aluminium. J Mater Sci 1998;33 (5):1243-51.

[24] Hatamleh O. Effects of peening on mechanical properties in friction stir welded 2195 aluminum alloy joints. Mater Sci Eng a-Struct Mater Prop Microstruct Process 2008:492(1-2):168-76.

[25] Woo W et al. Prediction of hardness minimum locations during natural aging in an aluminum alloy 6061-T6 friction stir weld. J Mater Sci 2009;44 (23):6302-9.

[26] Hong YS et al. Propensities of crack interior initiation and early growth for very-high-cycle fatigue of high strength steels. Int $\mathrm{J}$ Fatigue 2014;58:144-51.

[27] Huang ZY et al. Effect of carburizing treatment on the "fish eye" crack growth for a low alloyed chromium steel in very high cycle fatigue. Mater Sci Eng aStruct Mater Prop Microstruct Process 2013;559:790-7.

[28] Shiozawa K, Morii Y, Nishino S. Subsurface crack initiation and propagation mechanism under the super-long fatigue regime for high speed tool steel (JIS SKH51) by fracture surface topographic analysis. JSME Int J Ser a-Solid Mech Mater Eng 2006;49(1):1-10.

[29] Lukas $P$ et al. Fatigue damage of ultrafine-grain copper in very-high cycle fatigue region. Mater Sci Eng a-Struct Mater Prop Microstruct Process 2011;528(22-23):7036-40 
[30] Stanzl-Tschegg SE, Schonbauer B. Mechanisms of strain localization, crack initiation and fracture of polycrystalline copper in the VHCF regime. Int J Fatigue 2010;32(6):886-93.

[31] Bathias C. Coupling effect of plasticity, thermal dissipation and metallurgical stability in ultrasonic fatigue. Int J Fatigue 2014:60:18-22.

[32] Müller-Bollenhagen C, Zimmermann M, Christ HJ. Very high cycle fatigue behaviour of austenitic stainless steel and the effect of strain-induced martensite. Int J Fatigue 2010;32(6):936-42.
[33] Smith FW, Emery AF, Kobayash As. Stress intensity factors for semicircular cracks. 2. Semi-infinite solid. J Appl Mech 1967;34(4):953.

[34] Paris PC, Tada H, Donald JK. Service load fatigue damage - a historical perspective. Int J Fatigue 1999;21:S35-46.

[35] Pawliska P, Richard HA, Diekmann P. The behavior of cracks in elastic-plastic materials under plane normal and shear loadings. Int J Fract 1993;62 (1):43-54. 